\title{
Nebulized anticoagulants in lung injury in critically ill patients - an updated systematic review of preclinical and clinical studies
}

\author{
Jenny Juschten ${ }^{1,2,3}$, Pieter R. Tuinman ${ }^{2}$, Nicole P. Juffermans ${ }^{1,3}$, Barry Dixon ${ }^{4}$, Marcel Levi $^{5}$, Marcus J. \\ Schultz ${ }^{1,3,6}$ \\ ${ }^{1}$ Laboratory of Experimental Intensive Care and Anesthesiology (L.E.I.C.A), Academic Medical Center, Amsterdam, the Netherlands; ${ }^{2}$ Department \\ of Intensive Care and Research VUmc Intensive Care (REVIVE), VU Medical Center, Amsterdam, the Netherlands; ${ }^{3}$ Department of Intensive Care, \\ Academic Medical Center, Amsterdam, the Netherlands; ${ }^{4}$ Department of Intensive Care Medicine, St. Vincent's Hospital, Melbourne, Australia; \\ ${ }^{5}$ Department of Medicine, University College London Hospitals, London, UK; ${ }^{6}$ Mahidol-Oxford Research Unit (MORU), Mahidol University, \\ Bangkok, Thailand \\ Contributions: (I) Conception and design: MJ Schultz; (II) Administrative support: None; (III) Provision of study materials or patients: None; (IV) \\ Collection and assembly of data: J Juschten, PR Tuinman; (V) Data analysis and interpretation: J Juschten, PR Tuinman, MJ Schultz; (VI) Manuscript \\ writing: All authors; (VII) Final approval of manuscript: All authors. \\ Correspondence to: Prof. Marcus J. Schultz, MD, PhD. Department of Intensive Care, Academic Medical Center, Amsterdam, the Netherlands. \\ Email: marcus.j.schultz@gmail.com.
}

\begin{abstract}
Pneumonia, inhalation trauma and acute respiratory distress syndrome (ARDS), typical causes of lung injury in critically ill patients, are all three characterized by dysregulated inflammation and coagulation in the lungs. Nebulized anticoagulants are thought to have beneficial effects as they could attenuate pulmonary coagulopathy and maybe even affect pulmonary inflammation. A systematic search of the medical literature was performed using terms referring to aspects of the condition ('pneumonia', 'inhalation trauma' and 'ARDS'), the intervention ('nebulized', 'vaporized', and 'aerosolized') and anticoagulants limited to agents that are commercially available and frequently given or tested in critically ill patients ['heparin', 'danaparoid', 'activated protein C' (APC), 'antithrombin' (AT) and 'tissue factor pathway inhibitor' (TFPI)]. The systematic search identified 16 articles reporting on preclinical studies and 11 articles reporting on human trials. All nebulized anticoagulants attenuate pulmonary coagulopathy in preclinical studies using various models for lung injury, but the effects on inflammation are less consistent. Nebulized heparin, danaparoid and TFPI, but not APC and AT also reduced systemic coagulation. Nebulized heparin in lung injury patients shows contradictory results, and there is concern over systemic side effects of this strategy. Future studies need to focus on the way to nebulize anticoagulants, as well as on efficient but safe dosages, and other side effects.
\end{abstract}

Keywords: Nebulization; anticoagulants; lung injury

Submitted Jul 10, 2017. Accepted for publication Jul 21, 2017.

doi: $10.21037 /$ atm.2017.08.23

View this article at: http://dx.doi.org/10.21037/atm.2017.08.23

\section{Introduction}

Inflammation and coagulation use widespread reciprocal activation and amplification in mounting a response against various injurious insults $(1,2)$. This makes sense when considering the immune response and clotting as maybe the oldest and most important host-protective systems that need to act simultaneously. For example, consider the role of inflammation and coagulation in a fresh wound caused by an animal bite-a rapid inflammatory response and generation of fibrin is essential for preventing further spreading of pathogens, while at the same time clotting is crucial to prevent the victim from bleeding to death. It is long known that these systems also collaborate in lung tissue. Indeed, 
inflammation (3-5) and clotting (5-7) are activated upon infectious as well as non-infectious pulmonary challenges, and also here these two probably act as brothers-in-arms. Consider the role of inflammation and coagulation in a pulmonary infection-immune cells like resident alveolar macrophages and recruited neutrophils, together with proinflammatory mediators initiate a protective inflammatory reaction to protect the host against the invading pathogens, while new-formed clots and microvascular clots occluding the draining venules add to host defense by restraining bacteria to the site of infection and preventing bacteria from reaching the systemic circulation.

However, both the immune response and clotting can be too firm resulting in unfavorable effects. Seen the crosstalk between coagulation and inflammation, they may further amplify each other in an ongoing and overwhelming response, resulting in collateral damage. For instance, in sepsis an uncontrolled systemic immune response combined with overactivation of the coagulation system could lead to diffuse endothelial damage, multiple organ dysfunction, consumption of clotting factors and widespread fibrin depositions, eventually causing death. A similar problem may exist in lung tissue, where overzealous inflammation and excessive fibrin deposition within the airways may result in damage the blood-lung barrier and surfactant dysfunction, eventually compromising pulmonary integrity and gas-exchange $(5,8,9)$.

Numerous randomized controlled trials in sepsis patients have tested various systemic immunomodulating as well as anticoagulant strategies - so far, these trials failed to show or to confirm benefit, and some trials even suggested harm of these strategies (10). These were followed by randomized controlled trials testing comparable strategies in patients with lung injury - and so far, also these trials failed to show beneficial effects (9). As systemic bleeding, due to systemic anticoagulation may offset possible positive effects, interest further moved to local anticoagulant approaches, i.e., through nebulization, in patients with lung injury. Nebulized anticoagulants may improve local biological availability, and as such may increase their efficacy in the lungs while lowering the risk of systemic bleeding complications $(9,11)$.

In the present review, we first provide a concise description of pulmonary coagulopathy in three typical examples of lung injury in critically ill patients, i.e., pneumonia, inhalation trauma and acute respiratory distress syndrome (ARDS). This is followed by an updated systematic review of nebulization of anticoagulants (11) in these three types of lung injury in which we searched for evidence for benefit of local treatment with anticoagulant agents in preclinical studies using animal models as well as clinical trials in intensive care unit (ICU)-patients.

\section{Concise description of pulmonary coagulopathy}

Prominent changes in concentration of markers of coagulation in bronchoalveolar fluid have been described in patients with pneumonia (6), inhalation trauma (12), and patients with ARDS $(6,13)$. While less prominent alterations are seen in spontaneously pneumonia patients who breath without mechanical ventilatory support (6), the extent of changes in patients with severe pneumonia mandating invasive mechanical ventilation are nearly identical to patients with ARDS, in whom pulmonary changes in coagulation are usually more abundant $(6,13)$. Similar alterations in bronchoalveolar coagulation have been described in burn patients with inhalation trauma, where severity of inhalation trauma is associated with the extent of the pulmonary coagulopathy (12).

\section{Thrombin generation}

Alveolar thrombin generation in pneumonia, inhalation trauma and ARDS are mediated by the tissue factor (TF)factor VIIa pathway $(7,12,14,15)$. TF levels are low in the normal lung but elevated in disease $(16,17)$. Patients who develop pneumonia (7), burn patients with inhalation trauma (12), and patients with ARDS (18) all demonstrate increases in bronchoalveolar levels of thrombinantithrombin (TAT) complexes, which is associated with a simultaneous rise in alveolar levels of soluble TF and factor VII. Of note, pulmonary coagulopathy is merely a localized process, with changes in fibrin generation being restricted to the lungs, and in cases of unilateral pneumonia being restricted to the affected side $(19,20)$.

\section{Natural anticoagulant patbways}

Although lung tissue has only a limited capacity to produce protein C, activated protein C (APC) is present in alveoli (21). Patients with pneumonia $(22,23)$, burn patients with inhalation trauma (12), and patients with pulmonary inflammation all show a suppressed protein C system (24). This suppression is thought to be dependent on oxidation of thrombomodulin and shedding of thrombomodulin from the cell surface (25), resulting in soluble fragments of thrombomodulin in e.g., patients with ARDS (26), where higher thrombomodulin 
levels are associated with worse clinical outcomes. Relatively low levels of antithrombin (AT) are present in the lung and AT is rapidly consumed during low-dose endotoxemia $(27,28)$. The importance of AT in the pathogenesis of endotoxininduced lung injury, however, is underlined by studies in rats challenged with experimental endotoxemia (29). The exact role of tissue factor pathway inhibitor (TFPI) in the lung is less well known. In patients with interstitial lung disease it seems that insufficient TFPI is produced to adequately block pulmonary TF activity (30), and a similar mechanism has been suggested for patients with ARDS.

\section{Fibrinolysis}

In association with enhanced fibrin production, fibrinolytic activity is depressed in alveolar fluids of patients with pneumonia $(7,20,22)$, patients with inhalation trauma (12), and patients with ARDS (6). Depressed fibrinolytic activity is related to high pulmonary concentrations of the main inhibitor of fibrinolysis in lung tissue, plasminogen activator inhibitor type 1 (PAI-1). The importance of the fibrinolytic system in the pathogenesis of pneumonia is underscored by the observation that a depression of bronchoalveolar fibrinolysis precedes the clinical occurrence of pneumonia by several days (7). Bronchoalveolar fluid levels of PAI-1 are increased in burn patients with inhalation trauma and in patients with ARDS $(12,31)$ and is probably secreted by lung epithelial cells, fibroblasts, and endothelial cells $(32,33)$. Alveolar levels of PAI-1 are associated with higher mortality in patients with ARDS (31).

\section{Updated search strategy}

In May 2017 we repeated the systemic literature search on which we reported in a systematic review of preclinical and clinical investigations of nebulized anticoagulants in 2012 (11). For this updated review, the search strategy was expanded to cover the three types of lung injury frequently seen in critical care setting, i.e., pneumonia, inhalation trauma, and ARDS.

\section{Data sources and keywords}

To identify relevant reports on studies testing local anticoagulation in pneumonia, inhalation trauma and ARDS, an electronic search in Medline and Embase databases was conducted. The reference lists of retrieved papers were screened for potentially important papers.
The search was limited to papers published from 1980 until now, and papers written in English. The Medline and EMBASE databases were used to identify medical subject headings $(\mathrm{MeSH})$ to select search terms. In addition to MeSH-terms, free text words were used. Search terms referred to aspects of the condition ('pneumonia', 'inhalation trauma' and 'ARDS'). In addition, we searched on the intervention ('nebulized', 'vaporized', and 'aerosolized'), and various anticoagulant agents, but limited to agents that are commercially available and frequently given to critically ill patients ('heparin' and 'danaparoid') or those that have been tested in previous trials of sepsis ('APC', 'AT' and TFPI).

\section{Study selection and data extraction}

Titles and abstracts of identified manuscripts were reviewed on the subjects (i.e., animal models of lung injury, and ICU patients with pneumonia, burn patients with inhalation trauma, or critically ill patients with ARDS), the intervention (i.e., nebulized anticoagulation), and outcomes (i.e., lung injury and inflammation, pulmonary coagulation, systemic coagulation and bleeding). In case of uncertainty the complete manuscript was obtained and evaluated. Manuscripts were critically appraised for the effects of nebulized anticoagulants on pulmonary coagulation, parameters of lung injury, and outcome.

\section{Results}

\section{Search results}

The systematic search of the literature identified 16 articles reporting on preclinical studies (34-49) and 12 articles reporting on human trials (50-61) of nebulized anticoagulants. Details regarding article selection are presented in Figure 1. Compared to our previous review published in 2012, the updated search found six additional articles reporting on preclinical studies $(36,37,42-45)$, and eight new articles reporting on human trials of nebulized anticoagulants $(50,51,53-56,60,61)$.

The models used and outcomes reported in preclinical studies varied widely, but all more or less mimicked pulmonary infection, inhalation trauma, or ARDS in the human setting; these studies also used different anticoagulants at various dosages (see Table 1 for details). The human trials included critically ill patients with inhalation trauma or patients with, or an increased risk 

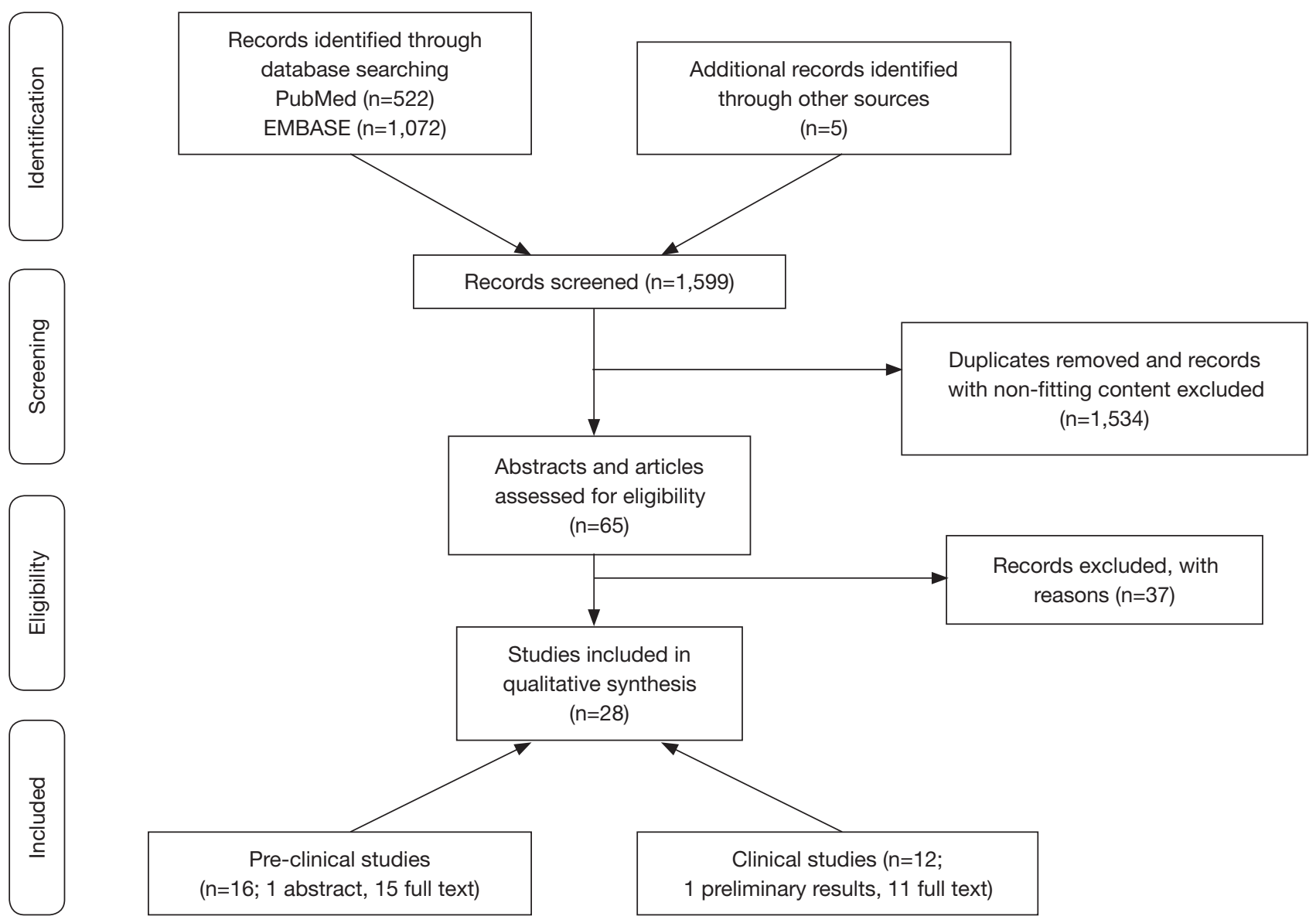

Figure 1 Prisma flow diagram showing the results of literature search and selection strategy.

for ARDS; all these trials tested only one anticoagulant, i.e., nebulized heparin. Of note, in some trials heparin was combined with mucolytics and/or bronchodilators (see Table 2 for details).

\section{Preclinical studies testing nebulized anticoagulants}

\section{Heparin}

In studies reporting on pulmonary coagulation markers, nebulized heparin was found to have a markedly anticoagulant effect in the lungs in the presence of pulmonary infection $(35,36)$ or lung injury $(49)$. In studies reporting on pulmonary inflammation, nebulized heparin also inhibited pulmonary inflammation in the presence of pulmonary infection $(35,36)$ or lung injury $(43,44)$, and in two studies using an inhalation trauma model $(40,41)$.
Nebulized heparin also affected various physiologic parameters and other outcomes, in particular during pulmonary infection $(34,35)$, and inhalation trauma (38-42). An effect of nebulized heparin on systemic coagulation was reported in one study using a lung injury model (49), but not in studies using pulmonary infection models $(36,49)$ or inhalation trauma models (38-42). None of these studies, however, showed systemic bleeding. Interestingly, more blood stream infections were noted in one study using a pulmonary infection model, although this finding was not statistically significant (35).

\section{Danaparoid}

Nebulized danaparoid also had clear anticoagulant effects in the lungs in studies using pulmonary infection models $(35,36)$ or lung injury model (49). An anti-inflammatory effect of nebulized danaparoid was only found in a study using a 


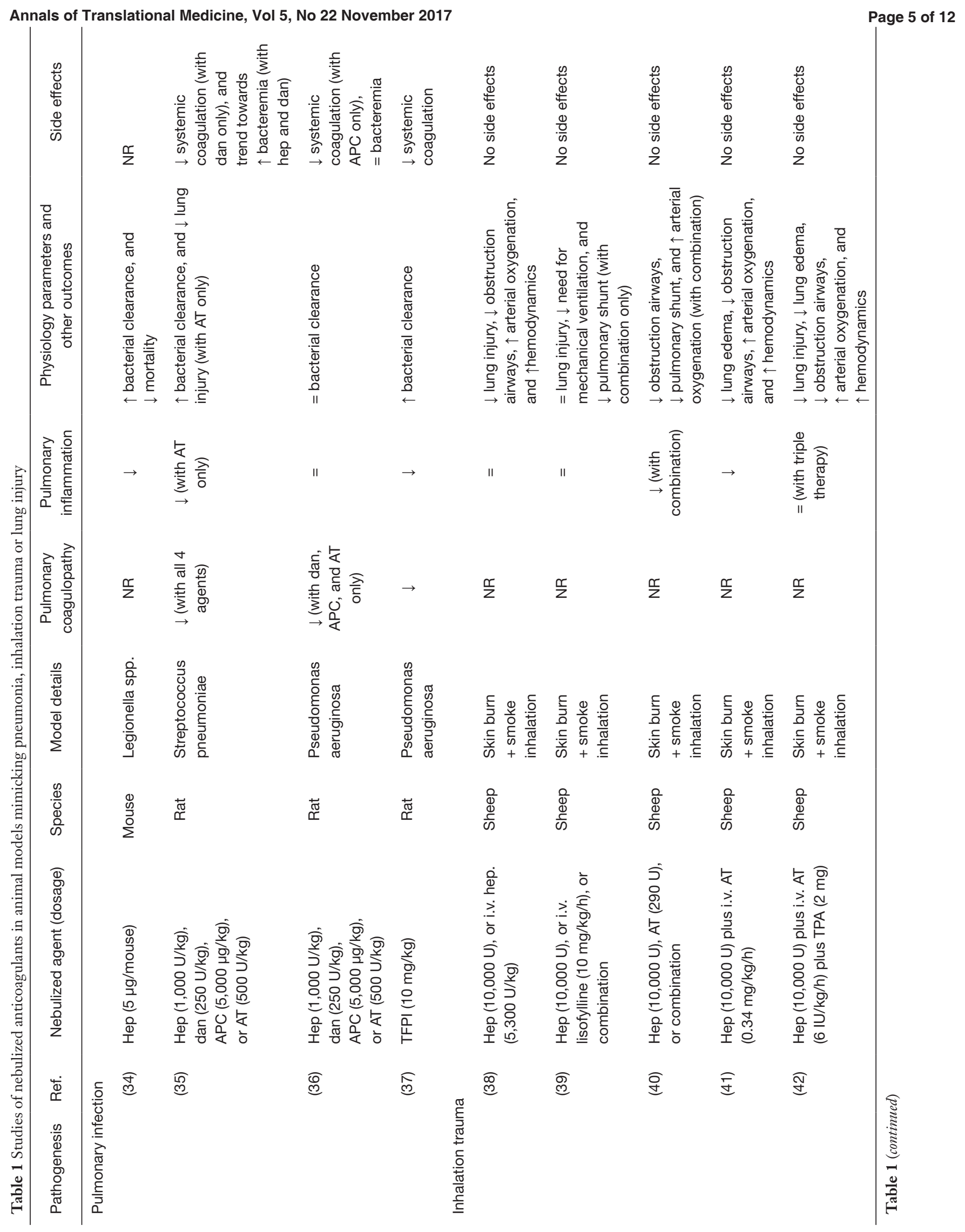




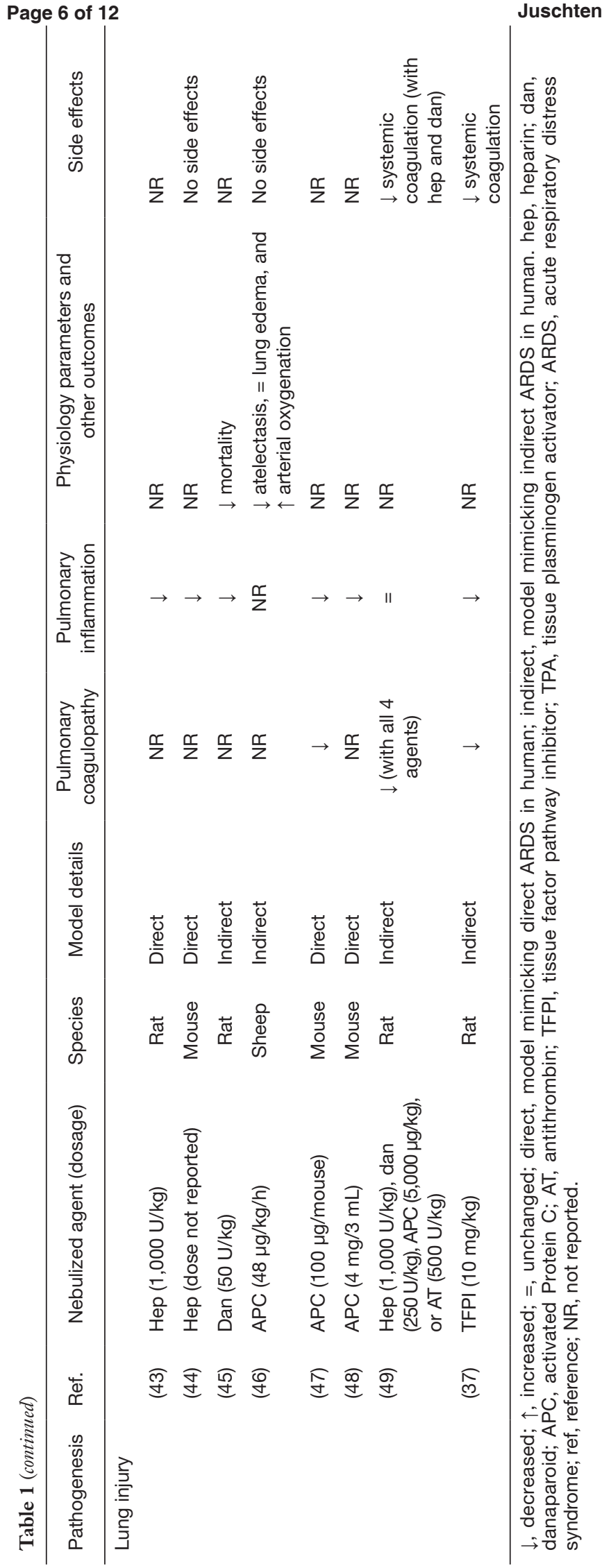

lung injury model (45). None of the studies of nebulized danaparoid reported on physiologic parameters. Nebulized danaparoid was found to have a systemic anticoagulant effect during pulmonary infection (35) and lung injury (49). None of these studies, however, showed systemic bleedings. Also, nebulized danaparoid was associated with a statistically nonsignificant rise in blood stream infections in one of the two studies using a pulmonary infection model (35).

APC

Nebulized APC attenuated pulmonary coagulopathy in studies using pulmonary infection models $(35,36)$ and studies using lung injury models $(47,49)$. Nebulized APC was associated with anti-inflammatory effects in two out of the three studies in animals with lung injury $(47,48)$, but not in studies in animals with a pulmonary infection $(35,36)$. In studies reporting on physiologic endpoints, nebulized APC improved physiological parameters in one study using a lung injury model (46), and not in studies using pulmonary infection models $(35,36)$. Effects on systemic coagulation were found in only one of the studies in animals with pulmonary infection (36), and not in studies in animals with lung injury (49). In none of the studies systemic bleedings were found.

\section{$A T$}

Nebulized AT also mitigated pulmonary coagulopathy in studies in animals with pulmonary infection $(35,36)$ or lung injury (49). An anti-inflammatory effect was described in only one of the studies in animals with a pulmonary infection (35), and not in animals with lung injury (49). In the two studies reporting physiologic endpoints, in one nebulized AT improved physiological parameters in animals with pulmonary infection. Nebulization of AT did not affect systemic coagulation and was not associated with systemic bleedings.

\section{Recombinant buman TFPI}

Finally, also nebulized TFPI reduced pulmonary coagulopathy, in animals with a pulmonary infection and in animals with lung injury (37). Effects on inflammation, physiological parameters or blood stream infections were not reported. Also, systemic coagulation was affected, but not systemic bleeding (37). 


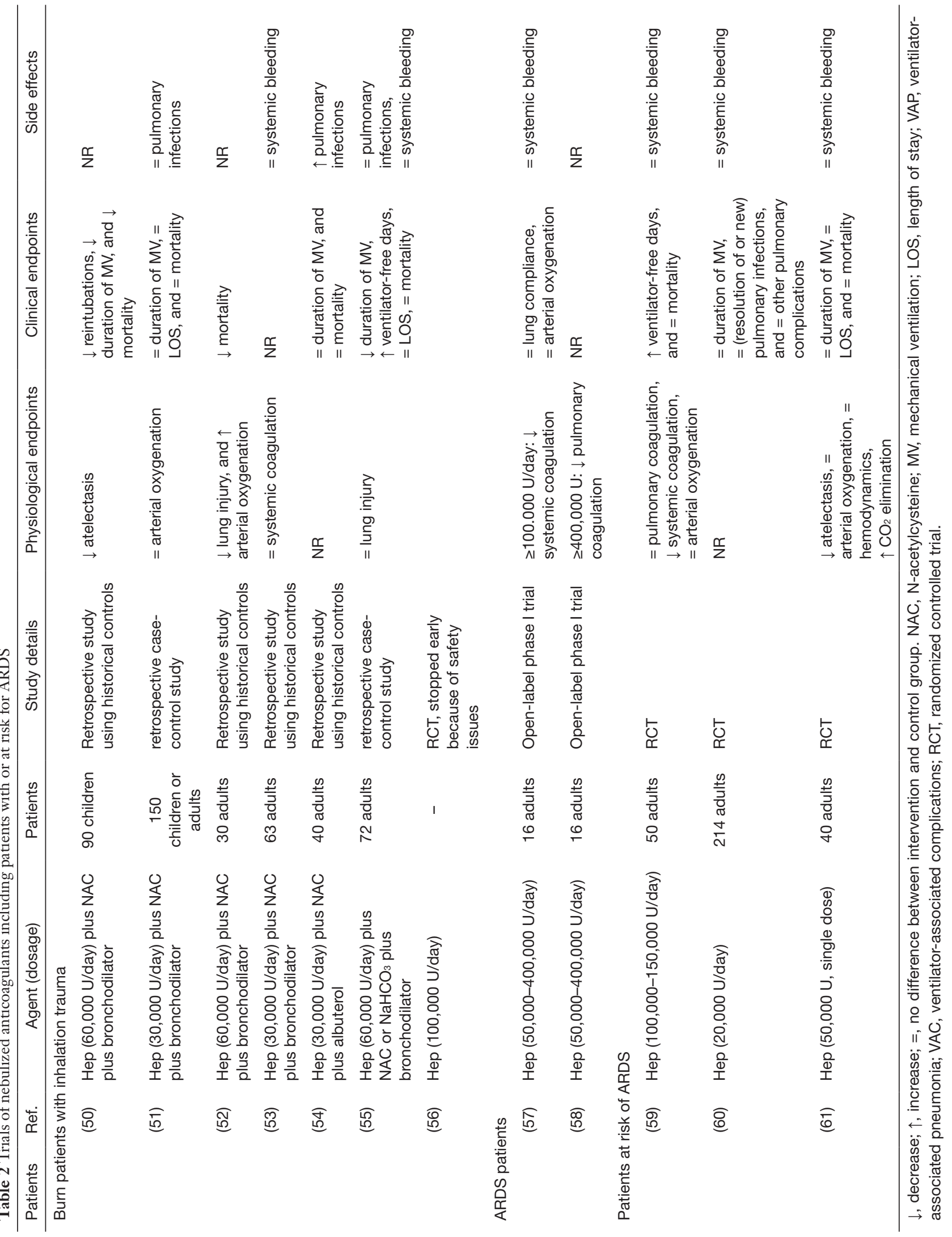




\section{Combination therapy using more than one anticoagulant}

None of these studies reported effects on pulmonary or systemic coagulation. Combining nebulized heparin with nebulized AT markedly improved pulmonary inflammation and physiological parameters in one study of inhalation trauma (40). Notably, combination of both anticoagulants resulted in more pronounced attenuation of inflammatory and physiological parameters than treatment with one agent alone.

Combining nebulized heparin with intravenously administered AT markedly decreased pulmonary inflammation and improved physiological parameters in a study of inhalation trauma (41), while combining nebulized heparin with intravenously administered lisofylline improved physiological parameters, but inflammation in a study using a similar model (39). Combining nebulized heparin with nebulized tissue plasminogen activator (TPA) and intravenously administered AT did not affect inflammation, but also significantly improved physiological parameters in a study of inhalation trauma (42). None of the studies of combined therapies showed more systemic bleeding or blood stream infections.

\section{Trials of nebulized anticoagulants in humans}

The search failed to identify trials in pneumonia patients. Quality of evidence coming from most articles was rather low due to limitations in study design, and because most trials were small.

\section{Trials in patients with inbalation trauma}

The trials in patients with inhalation trauma evaluated heparin in combination with $\mathrm{N}$-acetylcysteine and a bronchodilator. None of these studies reported on pulmonary coagulation or inflammation endpoints. Nebulized heparin was associated with physiologic improvements, but the physiologic endpoints varied widely. Nebulized heparin was associated with shorter duration of ventilatory support in two trials $(50,55)$, and with reduced mortality in two trials $(50,52)$, both retrospective trials using historical controls. Nebulization of heparin did neither affect systemic coagulation nor resulted in more systemic bleedings $(53,55)$. Of note, in one prematurely stopped randomized controlled trial, the incidence of blood-tinged sputum and increased systemic clotting times was high (personal communication) (56). Nebulized heparin was associated with an increased incidence of pneumonia in one trial that reported this outcome (54).

\section{Trials in patients with ARDS}

One phase I trial testing various dosages of nebulized heparin showed a reduction of pulmonary coagulopathy at dosages $\geq 400,000 \mathrm{U} /$ day. Effects in inflammation were not reported in that trial. Nebulized heparin did not affect physiological parameters, such as arterial oxygenation or pulmonary compliance. At dosages $\geq 100,000 \mathrm{U}$, systemic coagulation was affected, but without differences in bleeding incidences between the study groups (57).

\section{Trials in patients with an increased risk for ARDS}

Three well-conducted randomized controlled trials assessed the effects of nebulized heparin in patients that could be considered to be at increased risk of ARDS (59-61). Two trials included patients requiring prolonged mechanical ventilation $(59,60)$, and one trial assessed the effect of a prophylactic single heparin dosage before surgeries requiring a cardiopulmonary bypass (CPB) (61). Nebulized heparin did not affect pulmonary coagulation (59), and effects on inflammation were not reported. Neither did heparin nebulization improve arterial oxygenation $(59,61)$ nor hemodynamics (61). A single dosage of nebulized heparin prior to CPB surgery decreased atelectasis and improved $\mathrm{CO}_{2}$ elimination directly after the operation (61). Nebulized heparin increased the number of ventilator-free days in one trial (59), but duration of mechanical ventilation was not different between study groups in two other trials $(60,61)$. Nebulized heparin was not associated with mortality $(59,61)$. Nebulized heparin affected systemic coagulation (59), but did not result in differences in systemic bleedings (59-61). Heparin nebulization did not reduce the incidence of ventilator-associated pneumonia and other ventilatorassociated complications in a trial using a very low heparin dosage of 20,000 U/day (60).

\section{Discussion}

In this systematic review, we investigated the effects of nebulized anticoagulants in three relevant categories of lung injury, i.e., pneumonia, inhalation trauma and ARDS. The preclinical studies tested various anticoagulants; the human trials have only tested heparin, and only in the setting of inhalation trauma, and increased risk for or established ARDS. The findings can be summarized as follows: (I) nebulized anticoagulants exert anticoagulant effects in the lungs, an effect found with all tested agents, 
i.e., heparin, danaparoid, APC, AT and TFPI; (II) nebulized anticoagulants also have anti-inflammatory effects in the lungs, but this was not confirmed in all models and not with all agents; (III) nebulized heparin, danaparoid and TFPI, but not APC and AT affect systemic coagulation; and (IV) results of nebulized heparin in human trials are yet inconclusive to draw firm conclusions on its efficacy and safety.

The results of this systematic review expand our knowledge from previous reviews as it identified several new articles. This updated review particularly includes several new articles on human trials offering valuable clues regarding safety and other potential side effects of heparin nebulization. Other strengths of this systematic review are its translational approach of the literature, and reporting the results of preclinical studies using relevant preclinical models of lung injury and those of trials in ICU patients with frequently seen forms of pulmonary injury. Also, the search had no restrictions with respect to nebulized agents other than that they should be available for use, or must have been tested in trials in humans. In addition, the search had no restrictions with respect to the way anticoagulant agents were nebulized.

A recently published individual patient data meta-analysis on nebulized heparin in mechanically ventilated patients found no difference in any lung injury outcome after a propensity score matched analysis (62). This individual patient data meta-analysis included patients from several trials reviewed here. The effects on systemic coagulation and the high incidence of blood-tinged sputum in the recent trial of nebulized inhalation trauma patients (56) may be seen as an argument against its use, at least in this patient category and at the used dose.

All tested anticoagulants mitigated pulmonary coagulopathy in preclinical studies. Notably, pulmonary coagulopathy was not a primary outcome in any of the clinical trials, but one trial testing various dosages of nebulized heparin in patients with mild ARDS (58) found an inhibition of pulmonary coagulation. Of note, in this trial pulmonary coagulopathy was only inhibited at a dosage of above 400,000 U/day, whereas systemic coagulation was affected already at a dosage of above 100,000 U/day. Dosages in animal studies affecting pulmonary coagulation were found to be much lower $(35,49)$. This discrepancy raises the question if results from preclinical studies can be translated into the human setting.

While all anticoagulants attenuated pulmonary coagulopathy, anti-inflammatory effects were detected only sporadically (see Table 1 for details). The reasons for not finding an inhibitory effect on inflammation in all studies remain unexplained. Interestingly, one animal study combining nebulized heparin with AT found antiinflammatory effects, while 'triple therapy' by adding TPA abolished the inhibitory effect on inflammation (42). Hence, anticoagulants may induce anti-inflammatory effects due to pathways crosslinking coagulation and inflammation in models of lung injury; however, combination of various anticoagulants and dosages are of importance in influencing these mechanisms.

The quality of evidence for efficacy of nebulized heparin remains very limited, as only four randomized controlled trials have been performed to date (56,59-61). Besides, results of these trials are contradictory. Various factors could have an effect on the efficacy of nebulized heparin, like types of nebulizers used, and timing and dosages of nebulization. Indeed, different nebulizers were used in the trials, like jet nebulizers $(60)$ and mesh nebulizers $(56,57,59,60)$ leading to differences in efficacy of aerosol delivery. The wide range of administered heparin dosages (from very low 20,000 U/day to as high as 400,000 U/day, see Table 2 for details), may also explain the different findings. Additionally, there was a wide variety of underlying pathologies in the studied patients, from inhalation trauma to ARDS.

Most of the trials in human were performed in patients with inhalation trauma-representing a very distinct category of lung injury. Interpretation of the results of the trials in these patients knows several challenges. First, massive airway obstructive casts resulting in atelectasis, alveolar hyperinflation, and even pneumonia are major characteristics of this insult $(40,41,63)$. The effects of nebulized heparin on cast formation in these patients may not be comparable, or as important, to those in other patient categories. Second, nebulized heparin was frequently combined with $\mathrm{N}$-acetylcysteine and/or bronchodilators making it impossible to distinguish individual effects of the inhalation agents. Third, most of the trials in inhalation trauma patients used a retrospective design with historical controls making these trials susceptible to selection bias, poor quality of extracted data and missing confounding variables. Trials in patients with an increased risk for or with established ARDS were better designed but still suffer from several weaknesses. These trials were all single-center studies in very heterogeneous patient groups. Notably, many patients in these trials also received systemic heparin, which could have blurred the findings (59).

Nebulized anticoagulants could exert two major side effects. First, there is the risk of bleeding, either locally or 
systematically. Local bleedings probably were insufficiently reported in most trials. Nebulized anticoagulants can reach systemic circulation posing an additional safety concern by means of an increased risk of systemic bleeding. While an animal study showed that nebulized heparin indeed affects systemic coagulation (49), results from clinical trials are less consistent with regards to systemic effects of nebulized heparin. The only trial evaluating safety of nebulized heparin in inhalation trauma patients did not detect differences in systemic coagulation or systemic bleedings between intervention and control group (53). However, this trial used a relative low heparin dosage of $30,000 \mathrm{U} /$ day. Systemic coagulation effects were reported at heparin dosages above $100,000 \mathrm{U} /$ day in two trials of patients with or at risk for ARDS $(57,59)$. None of these trials, though, reported increased incidences of bleedings with the intervention. One other potential side effect is destruction of a clot that may help preventing blood stream infections in case of pneumonia. In one preclinical study, more blood stream infections were noticed in rats treated with heparin or danaparoid (35). This was not confirmed by other preclinical studies in animals with a pulmonary infection, but maybe this was not looked for. The very same may be true for the trials in humans.

Quality of this systemic review is limited due to large heterogeneity of included articles of animal studies and human trials. Preclinical studies and clinical trials vary greatly in, e.g., study design, technique of nebulization and determined endpoints. Besides, nebulized heparin was always tested with concomitant nebulized interventions in human trials.

In conclusion, nebulized anticoagulants can attenuate pulmonary coagulopathy in preclinical studies using various models for lung injury. Nebulized heparin in lung injury patients show contradictory results, and there is concern over the side effects of this intervention. Future studies need to focus on the best way to nebulize anticoagulants, the best dosages, and on its possible role in spread of localized infections.

\section{Acknowledgements}

None.

\section{Footnote}

Conflicts of Interest: The authors have no conflicts of interest to declare.

\section{References}

1. Esmon CT. Crosstalk between inflammation and thrombosis. Maturitas 2004;47:305-14.

2. Levi M, van der Poll T, Buller HR. Bidirectional relation between inflammation and coagulation. Circulation 2004;109:2698-704.

3. Boutten A, Dehoux MS, Seta N, et al. Compartmentalized IL-8 and elastase release within the human lung in unilateral pneumonia. Am J Respir Crit Care Med 1996;153:336-42.

4. Dehoux MS, Boutten A, Ostinelli J, et al. Compartmentalized cytokine production within the human lung in unilateral pneumonia. Am J Respir Crit Care Med 1994;150:710-6.

5. Pugin J, Verghese G, Widmer MC, et al. The alveolar space is the site of intense inflammatory and profibrotic reactions in the early phase of acute respiratory distress syndrome. Crit Care Med 1999;27:304-12.

6. Gunther A, Mosavi P, Heinemann S, et al. Alveolar fibrin formation caused by enhanced procoagulant and depressed fibrinolytic capacities in severe pneumonia. Comparison with the acute respiratory distress syndrome. Am J Respir Crit Care Med 2000;161:454-62.

7. Schultz MJ, Millo J, Levi M, et al. Local activation of coagulation and inhibition of fibrinolysis in the lung during ventilator associated pneumonia. Thorax 2004;59:130-5.

8. Abraham E. Coagulation abnormalities in acute lung injury and sepsis. Am J Respir Cell Mol Biol 2000;22:401-4.

9. Schultz MJ, Haitsma JJ, Zhang H, et al. Pulmonary coagulopathy as a new target in therapeutic studies of acute lung injury or pneumonia--a review. Crit Care Med 2006;34:871-7.

10. van der Poll T. Immunotherapy of sepsis. Lancet Infect Dis 2001;1:165-74.

11. Tuinman PR, Dixon B, Levi M, et al. Nebulized anticoagulants for acute lung injury - a systematic review of preclinical and clinical investigations. Crit Care 2012;16:R70.

12. Hofstra JJ, Vlaar AP, Knape P, et al. Pulmonary activation of coagulation and inhibition of fibrinolysis after burn injuries and inhalation trauma. J Trauma 2011;70:1389-97.

13. Fuchs-Buder T, de Moerloose P, Ricou B, et al.

Time course of procoagulant activity and D dimer in bronchoalveolar fluid of patients at risk for or with acute respiratory distress syndrome. Am J Respir Crit Care Med 1996;153:163-7.

14. Idell S, Gonzalez K, Bradford H, et al. Procoagulant activity in bronchoalveolar lavage in the adult respiratory 
distress syndrome. Contribution of tissue factor associated with factor VII. Am Rev Respir Dis 1987;136:1466-74.

15. Idell S, Koenig KB, Fair DS, et al. Serial abnormalities of fibrin turnover in evolving adult respiratory distress syndrome. Am J Physiol 1991;261:L240-8.

16. Jesmin S, Gando S, Matsuda N, et al. Temporal changes in pulmonary expression of key procoagulant molecules in rabbits with endotoxin-induced acute lung injury: elevated expression levels of protease-activated receptors. Thromb Haemost 2004;92:966-79.

17. Maris NA, de Vos AF, Bresser P, et al. Activation of coagulation and inhibition of fibrinolysis in the lung after inhalation of lipopolysaccharide by healthy volunteers. Thromb Haemost 2005;93:1036-40.

18. Miller DL, Welty-Wolf K, Carraway MS, et al. Extrinsic coagulation blockade attenuates lung injury and proinflammatory cytokine release after intratracheal lipopolysaccharide. Am J Respir Cell Mol Biol 2002;26:650-8.

19. Rijneveld AW, Weijer S, Florquin S, et al. Thrombomodulin mutant mice with a strongly reduced capacity to generate activated protein $\mathrm{C}$ have an unaltered pulmonary immune response to respiratory pathogens and lipopolysaccharide. Blood 2004;103:1702-9.

20. Choi G, Schultz MJ, van Till JW, et al. Disturbed alveolar fibrin turnover during pneumonia is restricted to the site of infection. Eur Respir J 2004;24:786-9.

21. Yamamoto K, Loskutoff DJ. Extrahepatic expression and regulation of protein $\mathrm{C}$ in the mouse. Am J Pathol 1998;153:547-55.

22. Choi G, Schultz MJ, Levi M, et al. Protein C in pneumonia. Thorax 2005;60:705-6.

23. Choi G, Bresser P, Levi M, et al. Disturbed alveolar fibrin turnover during pneumonia is associated with reduced activated protein C levels in lungs. Crit Care 2004;8:111.

24. Hataji O, Taguchi O, Gabazza EC, et al. Activation of protein C pathway in the airways. Lung 2002;180:47-59.

25. Levi M, Ten Cate H. Disseminated intravascular coagulation. N Engl J Med 1999;341:586-92.

26. Ware LB, Fang X, Matthay MA. Protein C and thrombomodulin in human acute lung injury. Am J Physiol Lung Cell Mol Physiol 2003;285:L514-21.

27. Levi M, van der Poll T, ten Cate H, et al. Differential effects of anti-cytokine treatment on bronchoalveolar hemostasis in endotoxemic chimpanzees. Am J Respir Crit Care Med 1998;158:92-8.

28. Chapman HA, Stahl M, Allen CL, et al. Regulation of the procoagulant activity within the bronchoalveolar compartment of normal human lung. Am Rev Respir Dis 1988;137:1417-25.

29. Okajima K. Antithrombin prevents endotoxin-induced pulmonary vascular injury by inhibiting leukocyte activation. Blood Coagul Fibrinolysis 1998;9 Suppl 2:S25-37.

30. de Moerloose P, De Benedetti E, Nicod L, et al. Procoagulant activity in bronchoalveolar fluids: no relationship with tissue factor pathway inhibitor activity. Thromb Res 1992;65:507-18.

31. Prabhakaran P, Ware LB, White KE, et al. Elevated levels of plasminogen activator inhibitor-1 in pulmonary edema fluid are associated with mortality in acute lung injury. Am J Physiol Lung Cell Mol Physiol 2003;285:L20-8.

32. Idell S. Endothelium and disordered fibrin turnover in the injured lung: newly recognized pathways. Crit Care Med 2002;30:S274-80.

33. Marshall BC, Sageser DS, Rao NV, et al. Alveolar epithelial cell plasminogen activator. Characterization and regulation. J Biol Chem 1990;265:8198-204.

34. Ader F, Le Berre R, Fackeure R, et al. In vivo effect of adhesion inhibitor heparin on Legionella pneumophila pathogenesis in a murine pneumonia model. Intensive Care Med 2008;34:1511-9.

35. Hofstra JJ, Cornet AD, de Rooy BF, et al. Nebulized antithrombin limits bacterial outgrowth and lung injury in Streptococcus pneumoniae pneumonia in rats. Crit Care 2009; 13:R145.

36. Cornet AD, Hofstra JJ, Vlaar AP, et al. Nebulized anticoagulants limit coagulopathy but not inflammation in pseudomonas aeruginosa-induced pneumonia in rats. Shock 2011;36:417-23.

37. van den Boogaard FE, Hofstra JJ, Brands X, et al. Nebulized Recombinant Human Tissue Factor Pathway Inhibitor Attenuates Coagulation and Exerts Modest Antiinflammatory Effects in Rat Models of Lung Injury. J Aerosol Med Pulm Drug Deliv 2017;30:91-9.

38. Murakami K, McGuire R, Cox RA, et al. Heparin nebulization attenuates acute lung injury in sepsis following smoke inhalation in sheep. Shock 2002;18:236-41.

39. Tasaki O, Mozingo DW, Dubick MA, et al. Effects of heparin and lisofylline on pulmonary function after smoke inhalation injury in an ovine model. Crit Care Med 2002;30:637-43.

40. Enkhbaatar P, Cox RA, Traber LD, et al. Aerosolized anticoagulants ameliorate acute lung injury in sheep after exposure to burn and smoke inhalation. Crit Care Med 2007;35:2805-10.

41. Enkhbaatar P, Esechie A, Wang J, et al. Combined 
anticoagulants ameliorate acute lung injury in sheep after burn and smoke inhalation. Clin Sci (Lond) 2008;114:321-9.

42. Rehberg S, Yamamoto Y, Sousse LE, et al. Antithrombin attenuates vascular leakage via inhibiting neutrophil activation in acute lung injury. Crit Care Med 2013;41:e439-46.

43. Chimenti L, Guillamat R, Gomez N, et al. Effects of nebulized heparin on pulmonary inflammation in a rat model of acute lung injury. Eur Respir J 2015;46:PA2138.

44. Zarogiannis SG, Wagener BM, Basappa S, et al. Postexposure aerosolized heparin reduces lung injury in chlorine-exposed mice. Am J Physiol Lung Cell Mol Physiol 2014;307:L347-54.

45. Hagiwara S, Iwasaka H, Hidaka S, et al. Danaparoid sodium inhibits systemic inflammation and prevents endotoxin-induced acute lung injury in rats. Crit Care 2008;12:R43.

46. Waerhaug K, Kuzkov VV, Kuklin VN, et al. Inhaled aerosolised recombinant human activated protein $\mathrm{C}$ ameliorates endotoxin-induced lung injury in anaesthetised sheep. Crit Care 2009;13:R51.

47. Slofstra SH, Groot AP, Maris NA, et al. Inhalation of activated protein $\mathrm{C}$ inhibits endotoxin-induced pulmonary inflammation in mice independent of neutrophil recruitment. Br J Pharmacol 2006;149:740-6.

48. Kotanidou A, Loutrari H, Papadomichelakis E, et al. Inhaled activated protein $\mathrm{C}$ attenuates lung injury induced by aerosolized endotoxin in mice. Vascul Pharmacol 2006;45:134-40.

49. Hofstra JJ, Vlaar AP, Cornet AD, et al. Nebulized anticoagulants limit pulmonary coagulopathy, but not inflammation, in a model of experimental lung injury. $\mathrm{J}$ Aerosol Med Pulm Drug Deliv 2010;23:105-11.

50. Desai MH, Mlcak R, Richardson J, et al. Reduction in mortality in pediatric patients with inhalation injury with aerosolized heparin/ $\mathrm{N}$-acetylcystine [correction of acetylcystine] therapy. J Burn Care Rehabil 1998;19:210-2.

51. Holt J, Saffle JR, Morris SE, et al. Use of inhaled heparin/ $\mathrm{N}$-acetylcystine in inhalation injury: does it help? J Burn Care Res 2008;29:192-5.

52. Miller AC, Rivero A, Ziad S, et al. Influence of nebulized unfractionated heparin and $\mathrm{N}$-acetylcysteine in acute lung injury after smoke inhalation injury. J Burn Care Res 2009;30:249-56.

53. Yip LY, Lim YF, Chan HN. Safety and potential anticoagulant effects of nebulised heparin in burns patients with inhalational injury at Singapore General Hospital

Burns Centre. Burns 2011;37:1154-60.

54. Kashefi NS, Nathan JI, Dissanaike S. Does a Nebulized Heparin/N-acetylcysteine Protocol Improve Outcomes in Adult Smoke Inhalation? Plast Reconstr Surg Glob Open 2014;2:e165.

55. McIntire AM, Harris SA, Whitten JA, et al. Outcomes Following the Use of Nebulized Heparin for Inhalation Injury (HIHI Study). J Burn Care Res 2017;38:45-52.

56. Glas GJ, Muller J, Binnekade JM, et al. HEPBURN investigating the efficacy and safety of nebulized heparin versus placebo in burn patients with inhalation trauma: study protocol for a multi-center randomized controlled trial. Trials 2014;15:91.

57. Dixon B, Santamaria JD, Campbell DJ. A phase 1 trial of nebulised heparin in acute lung injury. Crit Care 2008;12:R64.

58. Dixon B, Schultz MJ, Hofstra JJ, et al. Nebulized heparin reduces levels of pulmonary coagulation activation in acute lung injury. Crit Care 2010;14:445.

59. Dixon B, Schultz MJ, Smith R, et al. Nebulized heparin is associated with fewer days of mechanical ventilation in critically ill patients: a randomized controlled trial. Crit Care 2010;14:R180.

60. IPHIVAP investigators of the Australian and New Zealand Intensive Care Society Clinical Trials Group. Is inhaled prophylactic heparin useful for prevention and Management of Pneumonia in ventilated ICU patients? J Crit Care 2016;34:95-102.

61. Dixon B, Smith R, Santamaria JD, et al. A trial of nebulised heparin to limit lung injury following cardiac surgery. Anaesth Intensive Care 2016;44:28-33.

62. Glas GJ, Serpa Neto A, Horn J, et al. Nebulized heparin for patients under mechanical ventilation: an individual patient data meta-analysis. Ann Intensive Care 2016;6:33.

63. Enkhbaatar P, Murakami K, Cox R, et al. Aerosolized tissue plasminogen inhibitor improves pulmonary function in sheep with burn and smoke inhalation. Shock 2004;22:70-5.

Cite this article as: Juschten J, Tuinman PR, Juffermans NP, Dixon B, Levi M, Schultz MJ. Nebulized anticoagulants in lung injury in critically ill patients-an updated systematic review of preclinical and clinical studies. Ann Transl Med 2017;5(22):444. doi: 10.21037/atm.2017.08.23 